\title{
Impact of RFID on the Retail Value Chain:An Exploratory Study Using a Mixed Method Approach
}

\author{
Mithu Bhattacharya
}

\begin{abstract}
While several large retailers have mandated RFID deployment across their value chains, the case for RFID adoption in retail still remains uncertain. This paper aims at providing a realistic perspective of the immense potential of RFID, taking adoption drivers, potential benefits, and implementation challenges into account. In this paper, a mixed methodological approach is used that caters to the exploratory nature of the work to quantitatively analyze RFID adoption drivers, benefits, and implementation challenges. First content analysis is applied to analyze academic and trade articles to come up with key issues and concepts. The results from the content analysis acted as input for a Delphi study which is the second methodology. The combined results from the two methods provide deep insights and enhance understanding of important implementation issues related to RFID adoption in the retail sector and also aid in drawing meaningful managerial conclusions.
\end{abstract}

Keywords: rfid; retail; content analysis; delphi; new technology adoption. 


\section{Introduction}

Modern retail industry faces a number of challenges. The introduction of technologies like barcodes has not eliminated many issues such as: I) Out of stock: Out of stock situation is a big problem for the retail industry. According to (Gruen et al., 2002) average out-of stock level for the retail industry in United Stated is about 8.3\%. The root causes identified for the out of stock situation are inaccurate store ordering and forecasting, upstream activities, and inadequate shelf restocking.

2) Inventory inaccuracy: Inaccurate inventory is another problem that leads to huge losses for retailers. According to the case study results with a US based retailer (Raman, 2000) claimed that there was inaccurate inventory for over $70 \%$ of the stock keeping units in the store.

Radio Frequency Identification (RFID) is an example of automatic identification technology which is much more advanced than the barcode technology and can address these issues effectively through reduced manual intervention and thus errors. In this regard, (Bagchi et al., 2007) have shown that RFID stochastically dominated barcodes. This research work deals with the usage of RFID technology across the retail value chain. The basic idea of RFID technology revolutionizing the way business is conducted today is through RFID tags that uniquely identifies objects. The numbering scheme as proposed by the Auto-ID center used for unique identification is the Electronic Product Code (EPC).

The current adoption of RFID is primarily at the case and pallet levels. However item level tagging is where the future is as it will allow extreme visibility (Zhou, 2009). RFID adoption rolled out with large retailers such as Wal-Mart, Tesco,Albertsons, Best Buy, Marks and Spencer, Sears, Home Depot, Metro and government agencies such as DOD (US department of defense) and FDA (Food and Drug Administration) mandating their suppliers to tag their products at a pallet or case level with the objective of streamlining their value chain processes. The widespread use of RFID could automate individual items, cases or pallets of products, as well as reusable assets throughout the value chain. Real-time visibility could be a reality with RFID which was not possible with the use of bar-code technology.

Although businesses have performed pilot tests that have helped to identify the strengths and weaknesses of the technology, they are yet to proceed to where they can actually compare the value chain performance. And given the early stage of RFID adoption, there is uncertainty regarding the actual value and return of investments (ROI). In other words, there is a gap between the ideal vision and the current perception of businesses regarding the value of RFID. Hence, this work seeks to improve the understanding of the potential benefits of adopting RFID. Improved understanding is achieved by providing a comprehensive discussion of factors that influence the adoption of RFID, the benefits that RFID can offer, and finally the challenges that must be overcome. Rogers diffusion model (Rogers, 1995) is adapted to encapsulate the entire research problem. The various stages in the adapted model are knowledge, persuasion, design and decision, and implementation. The knowledge stage involves enhancing the required information about the various aspects of the technology. Thus, issues such as RFID adoption pros and cons, retail domain characteristics, and current RFID adoption status are linked with this stage. The persuasion stage of the diffusion model maps to RFID-adoption drivers and key benefits, and the decision and design stage incorporated activities that led to deciding whether to adopt or reject a particular RFID solution. The latter included identifying potential value chain activities, RFID-applicable business processes, and RFID technology choice (in terms of RFID frequency, standards, case/pallet level of tagging, and so on). For this paper, the only focus is on the persuasion stage involving adoption drivers, benefits, and implementation stage involving adoption challenges. The other stages and thus related issues are beyond the scope of this paper. The benefits or the effects of the RFID technology across the retail value chain are also investigated in terms of automational (automating operational processes eliminating or reducing manual intervention), informational (improved capabilities to collect, store, process, and disseminate information), and transformational (facilitating process reengineering) effects which are the primary constructs of the theory of business value of IT (Mooney et al., 1996; Dedrick et al., 2003).

Although it has been claimed that RFID is going to revolutionize the way businesses are conducted today, the adoption rate of the technology has been relatively slow. This study takes an in-depth look between promise and reality. This work could guide decision makers and inform consultants about relative importance of going forward for future adoption decisions. Rogers' technology diffusion model is used to conceptualize the way decision makers and organizations are persuaded to make the adoption decision and the focus is on key drivers and possible benefits. Perceived and actual implementation challenges are also important for the overall decision to adopt RFID.

In the next section the research questions are presented followed by the research methodology. Then related research work and the analytical results and discussion followed by conclusions are discussed. 


\section{Research Questions}

A value chain perspective is used in this research to study the drivers for RFID adoption, its benefits and, its challenges. The retail sector is chosen since this sector is heavily reliant on its value chain partners. Because this sector is one of the first to seriously consider RFID implementations, conduct pilot work and present findings, it is a rich source of data for content analysis. In addition it has enough experts spread across academics, consultants, practitioners, and third party service providers to conduct a robust Delphi study. Specifically, the following research questions are posed:

I. What are the significant adoption drivers for RFID in retail?

2. What are the benefits for RFID in retail?

3. What are the key challenges for RFID in retail? And

4. $\quad$ Are there any differences across expert perceptions regarding RFID adoption drivers, benefits, and implementation challenges?

\section{Research Methods}

Due to the fact that the use of RFID in retail sector for operational and value chain improvement is a rather new area it became clear during the research planning phase that the methodology must be suitable for the analysis of data. Therefore a combination of secondary and primary data sources provides data for this research work. Mixed method is appropriate since RFID research is still at its infancy and thus a combination of methodological techniques better assists in exploring the impact of the technology. The methodology is twofold. Content analysis is the first method that is used. Second, 'Delphi method' is used to cross check our findings as well as to unveil other pertinent issues that are deemed important. The two methods are well established scientific methods that are widely used in Information Science (IS) research and are suitable to meet our research objective.

\section{Content Analysis}

Content analysis is a research technique for making valid inferences from texts or other meaningful matter to the contexts of their use (Krippendorf, 2004). It is defined as the detailed and systematic examination of the contents of a particular body of materials for the purpose of identifying patterns, themes or biases. The methodology is both qualitative and quantitative (Leedy and Ormrod, 2005). The reason is that content analysis counts the frequency of occurrences of particular words in the text and provides a means for statistical analysis, thus making it quantitative. It also allows establishing relationships between themes making it qualitative as well. For content analysis phase relevant articles are first searched. The choice of articles to be included for analysis is restricted to those written from the year 2000 onwards. The search covered popular on-line sources, such as RFID Journal, RFID Gazette, TechRepublic, and major academic on-line databases, such as ABI INFORM, ACM Digital library, and IEEE Explore. Different versions of the keyword containing "RFID" and "Retail" are used and all relevant articles are collected. The search is conducted between October 2006 - April 2009 and 630 articles are retrieved: 58 published journal articles, 54 conference proceedings, 90 academic magazines, 234 industry white papers, and 194 news releases. For the news releases, the majority consisted of insights from pilot studies or actual RFID implementations and thus can be viewed as equally reliable as academic articles. Figure I shows the research framework. After collecting the data, the textual data is classified and each research issue is associated with a stage in the RFID diffusion model. The various issues that emerged in the classification phase are the following:

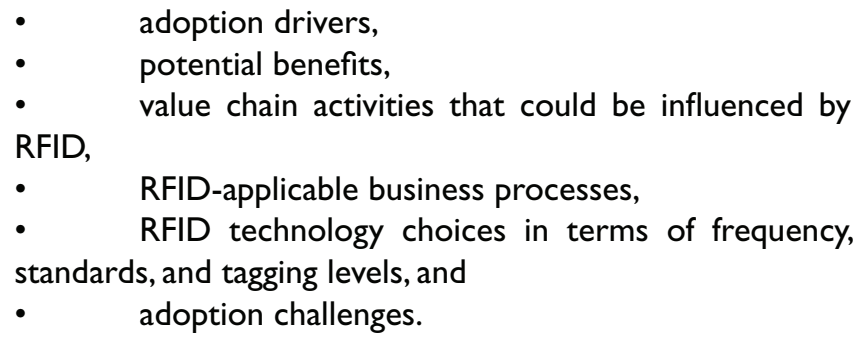

In order to ensure the reliability of data coding, the dataset is revisited three times during the coding process and thus the coding scheme was generated iteratively.To validate the manual coding scheme computer aided content analysis was performed using open source software program called textStat on a randomly selected $10 \%$ of the total number articles (which is 47 articles) from the data corpus. TextStat gives the frequency counts of each word within an article. This word frequency list was compared with the primary coding schema and was treated as the coding schema from a secondary coder. After comparing the two coding schemas, the level of coding agreement was calculated.

To ensure inter-coder reliability, (Holsti, 1969) formula for reliability was used.
Reliability $=2(\mathrm{OA}) /(\mathrm{NI}+\mathrm{N} 2)$
$\mathrm{OA}=$ Observed Agreement
$\mathrm{NI}=$ No. of coding decisions made by the primary coder
$\mathrm{N} 2=$ No. of coding decisions made by the secondary coder
Based on the above formula the level of agreement between primary manual coding scheme and secondary computer aided coding is $99.21 \%$. 


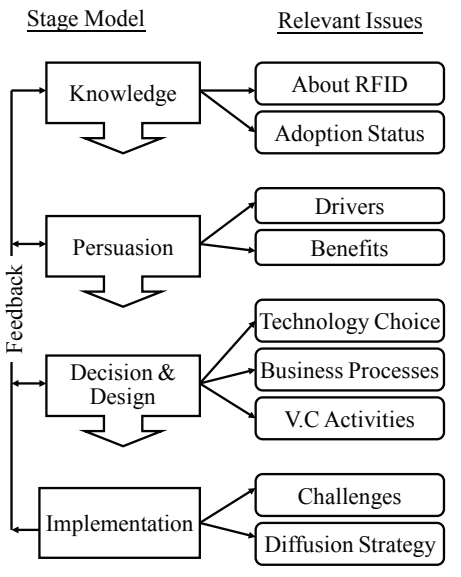

Figure I. Research framework

\section{Delphi Technique}

Delphi 'technique' is the second method used for this work. The Delphi 'technique' combines judgments from a panel of independent experts. This method is relevant when little hard data or well-established theory is available, but where experts have relevant judgments. It is based on the premise that aggregation reduces the error of individual responses. The Delphi technique dates to 1959 and was developed by Dalkey and Helmer of the Rand Corporation. According to (Dalkey, 1969) the Delphi method has three primary features: anonymity, controlled feedback and iteration, and formal group judgment. Each respondent submit independent answers to the relevant questions in the interview/ questionnaire. The results of a given round of responses are summarized and reported to the group who are then asked to reassess their replies in light of the feedback. Finally, the group's answer is presented as an aggregation given the final set of individual answers.

\section{Candidate Selection}

In order to reduce bias from a group composed of candidates of similar backgrounds candidates from different sectors such as consulting, academia (faculty researchers), retail, and third party service providers were obtained. This allowed achieving a broad overview and eliminating inherent bias in each sector. A total of 74 expert candidates, including consultants $(23 ; 31.1 \%)$ academics $(17 ; 23 \%)$ retail practitioners (16;21.6\%), and third-party service providers (18; $24.3 \%)$ participated in this research. It is also attempted to obtain the opinions of experts across the spectrum of management levels. Among the expert candidates, 28 (37.8\%) hold top management positions, 8 (10.8\%) hold IT management positions, 19 (25.7\%) are executives, and 19 (25.7\%) hold research positions. The experts are identified through personal contacts.

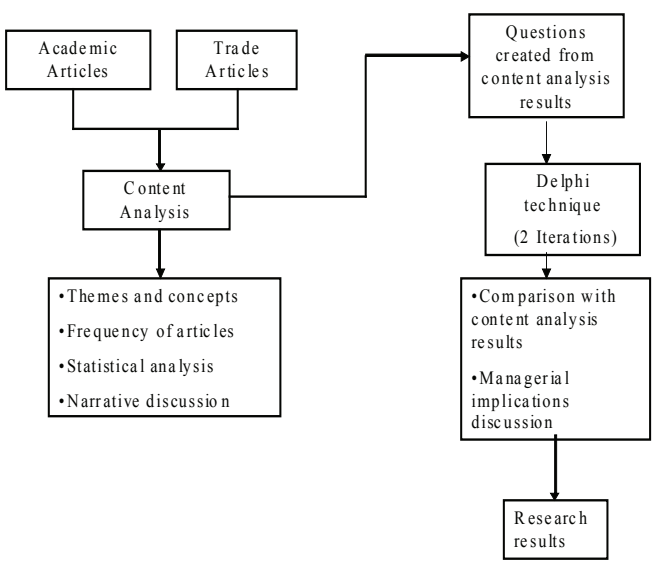

Figure 2. Research process

\section{Questionnaire Design}

The questionnaire guiding the Delphi study is generated primarily based on the previous research results from content analysis as well as under the guidance of the fundamental theories that serve as the premise of this work (Bhattacharya et al., 2007, 2008; 2009; 2010a). The questionnaire is pilot tested with graduate researchers and faculty members to enhance clarity and question focus. The questions are designed as 5 point Likert scale (Strongly disagree (I) to Strongly agree (5)). The validity of the measures is established using Cronbach's alpha to establish inter-item reliability. The Cronbach's alphas are high and ranged from 0.706 to 0.927 ( 0.706 for drivers; 0.927 for benefits; 0.794 for challenges).

\section{Research Procedure}

Figure 2 below shows the research diagram demonstrating the research process that is applied in this work. Academic and trade articles are analyzed using iterative content analysis. Next articles are classified and sorted based on the themes that emerged and those themes are then associated with the theoretical foundation of the Rogers diffusion model. The frequencies of the articles are used to support each theme and their sub-categories to find out the most significant factors among possible drivers, benefits, and challenges. These findings are then made input to the Delphi study. The Delphi study was conducted online between December 2009 and January 2010. After the questionnaire was developed it was sent to around 240 experts in electronic format through email. The web address of the questionnaire was provided in the email. The experts were identified through personal contacts. Two weeks later an email reminder was sent to request to respond to the questionnaire. After another two weeks around 80 responses were received, out of which 74 were deemed usable. The response rate is $30.84 \%$

ISSN: 07 I8-2724. (http://www.jotmi.org) 
which is a significantly high number and could be explained by the use of personal contacts and personalized methods to contact the candidates. In this study two iterations of the Delphi study are used. Not much new information is gained after the second round and thus no follow up rounds were conducted.

According to (Altschuld, 1993) two iterations are usually enough to obtain good estimate of the distribution and consensus view of participants and often not enough new information is gained to warrant the cost of more rounds.

\section{Related Research}

Studies of RFID and its applications cover a wide range of adoption characteristics, industry sectors, and geographical regions. Information provided from one entity within the supply chain to the other is the factor that differentiates the value-based supply chain from the traditional linear approach (Markland et al., 1995). The knowledge that improved information sharing leads to competitive advantage has caused businesses to invest more and more in enabling information technologies. And RFID when used in supply chain management can create and sustain a firm competitive advantage (Tajima, 2007).

RFID can be implemented in a variety of activities starting from the receipt of raw materials to the delivery to customers. Due to the considerably high cost of the RFID technology, it can be expensive to apply the technology to each step in the supply chain. Therefore the major challenge is to investigate individual company practices and determine the activities that would benefit the most from it. In the past few years, RFID has been expanding into the areas of tracking video cassettes in rental stores for better inventory management; tracking meat throughout processing facilities to monitor temperature; and tracking reusable containers as they are transferred between suppliers and manufacturers. The success of these applications has inspired industries to expand the technology across new horizons to better integrate the supply chain (Schmidt, 200I).

The advantage that RFID is expected to provide over bar codes include faster information retrieval, improved supply chain visibility, higher information content, and less probability of loss or theft (Hickey, 1999). Improved supply chain visibility and full or semi automation of rote operations are significant benefits that could be achieved from RFID implementation (Bose and Pal, 2005). Reducing the cost associated with lost products can lead to huge savings for companies that implement the technology (Roberti, 2002). Another benefit that RFID can provide when implemented within a supply chain is reduced shrinkage from employee or customer theft, vendor fraud or errors (Roberti, 2002) by provid- ing real-time information about the movement of goods and alerting security systems when unauthorized product movement is detected. The other area that could be significantly improved by using RFID is reduced stockouts (Bhattacharya et al., 2008, 2009, 2010; Karkkainen and Holmstrom, 2002). The technology leads to savings from improved inventory management, reduced employee error, replenishment productivity, and reduced stock loss (Karkkainen, 2003). Our previous content analysis study (Bhattacharya et al., 2010) suggests that better inventory management and improved security are the most significant benefits that RFID provides retailers. RFID provides real-time visibility, improved returns management, improved anti-theft capabilities, and improved customer service (Jones et al., 2004). RFID allows for greater speed and accuracy; reduced labor requirements; improved services within warehousing and distribution; and, finally, it eliminates checkout costs and allows for effective asset management within the retail and after-sales phase of the supply chain (Karkkainen and Holmstrom, 2002). (Ranky, 2006) suggests that RFID improves tracking and tracing of products and assets across the supply chain for manufacturers, distributors, and retailers, thus leading to a tighter supply chain and better customer service levels.

The business processes that are improved with RFID across a specific supply chain are identified to be receiving and put-away, picking, shipping, and replenishment (Wamba, et al., 2007; Bhattacharya et al., 20 I0b, 20 I I). Optimization of these processes can be achieved when RFID is used by eliminating or reducing manual interventions that is otherwise needed thus contributing to cost savings.

Future challenges that need to be overcome for wider RFID technology adoption are privacy, massive data management, high cost, and technical reliability issues (Jones, 2004; Lin et al., 2007; Metras, 2005; Vijayaraman and Osyk, 2006; Want, 2006). Also disputes regarding cost-benefit sharing, lack of standards, system integration, business process reengineering requirements, and the need for work force transformation will remain implementation challenges inhibiting RFID adoption (Bhattacharya et al., 2010; Ranky 2006).

\section{Descriptive Results and Discussion}

The results and discussion of this study are framed according to the stage in which they occur in the research model presented in Figure I. First, the key RFID adoption drivers and benefits associated with the persuasion stage are identified. Next, the adoption challenges associated with the implementation stage are discussed. The content analysis and Delphi study results are provided in Tables I, 3, and 5 showing the frequency and percentage of articles corresponding to a particular issue and the respondents rating average of the Likert scale responses from the Delphi study. Explora- 
tory factor analysis is performed on the Delphi data to identify the major dimensions of adoption drivers, benefits, and challenges using principal component analysis with Varimax rotation. Finally, an overall comparison of expert perceptions across business associations is provided.

\section{Major Drivers for RFID Adoption in Retail}

From the set of RFID articles, a total of $3 / 4$ instances are observed that mention one or more specific RFID adoption drivers. Given these instances, six RFID adoption drivers are identified as shown in Table I.

From content analysis it is observed that the big box retailer mandate is the most dominant driver for RFID adoption. The next most important driver is the government mandate (DOD, FDA etc.), followed by anti-counterfeiting requirements and EPC global initiatives for standardization. Next are the decreasing cost of tags and readers and technological maturity. Similar drivers for adoption are identified in the
Delphi study. However, the experts rated decreasing cost of tags and readers as the most significant adoption driver followed by RFID technological maturity and big box retailer mandates. Next are anti-counterfeiting requirements, government mandates, and EPC global initiatives for standardization.

Factor analysis of the initial 6 items of RFID drivers reveals two major factors: I) technological drivers and 2) environmental drivers. These factors accounts for $57.23 \%$ of the total variance. Specific factor items and factor loadings are shown in Table 2. These technological drivers are the innovation characteristics as developed in organizational adoption studies (Asif and Madviwalla, 2005; Orlikowski, 1993; Premkumar and Roberts, 1999; Ranganathan and Jha, 2005; Sharma and Citurs, 2005) and are consistent with constructs, such as complexity, cost, relative advantage, and compatibility for technological maturity, decreasing cost, anti-counterfeiting, and EPC global standardization initiatives respectively. The environmental drivers (retail and government mandates) are catalyst agents supporting RFID adoption.

\begin{tabular}{|l|c|c|}
\hline Drivers & $\begin{array}{c}\text { Frequency (Content } \\
\text { Analysis) }\end{array}$ & $\begin{array}{c}\text { Rating Average } \\
\text { (Delphi) }\end{array}$ \\
\hline Big box retailer mandates & $147(46.96 \%)$ & $3.71(3)$ \\
\hline Government mandates & $48(15.34 \%)$ & $3.38(5)$ \\
\hline Anti-counterfeiting & $41(13.10 \%)$ & $3.50(4)$ \\
\hline EPC global initiatives for standardization & $27(8.63 \%)$ & $3.15(6)$ \\
\hline Decreasing cost of tags and readers & $26(8.31 \%)$ & $3.85(1)$ \\
\hline Technological maturity & $24(7.67 \%)$ & $3.74(2)$ \\
\hline Total & $313(100 \%)$ & \\
\hline
\end{tabular}

Table I. RFID adoption drivers in retail

\begin{tabular}{|c|c|c|c|}
\hline Factors and items & Factor loadings & Eigen-value & \% of variance \\
\hline Technological drivers $(\alpha=0.703)$ & & 2.019 & 33.65 \\
\hline - $\quad$ Technological maturity & 0.822 & & \\
\hline $\begin{array}{l}\text { Decreasing cost of tags and read- } \\
\text { ers }\end{array}$ & 0.775 & & \\
\hline - Anti-counterfeiting & 0.596 & & \\
\hline$\quad \begin{array}{l}\text { EPC global initiatives for stan- } \\
\text { dardization }\end{array}$ & 0.574 & & \\
\hline Environmental drivers $(\alpha=0.596)$ & 0.815 & 1.640 & 27.34 \\
\hline - Big-box retailer mandates & 0.800 & & \\
\hline - Government mandates & & & \\
\hline
\end{tabular}

Table 2. Factor analysis of adoption drivers

ISSN: 07I 8-2724. (http://www.jotmi.org)

Journal of Technology Management \& Innovation (c) Universidad Alberto Hurtado, Facultad de Economía y Negocios. 


\section{Retailer Benefits of Adopting RFID}

Starting with the entire set of RFID articles, 1685 instances are observed that mention one or more specific RFID retailer benefits. These are shown in Table 3. From content analysis it is found that improved customer service levels, security against theft/fraud/loss/counterfeiting, reduced out of stock, improved data accuracy, and real time visibility are the most important reported benefits that RFID provides. Delphi study rankings are not consistent with these reported ranking of benefits. Experts from the Delphi study suggested that improved data accuracy, reduced out of stock, reduced missing sales, real time visibility, and reduced shrinkage are the top benefits that could be obtained through RFID implementation.
Factor analysis of the initial 22 items of RFID benefits reveals five factors with eigen-values above 1.0 that account for about $70 \%$ of the total variance. Potential benefits of RFID consisted of (a) improved operational efficiency, (b) improved inventory management, (c) improved customer, supplier coordination, (d) improved visibility, and (e) improved security. Specific factor loadings are shown in Table 4. These potential benefits have automational, informational, and transformational effects as developed in the theory of business value of IT (Dedrick et al., 2003; Mooney et al., 1996).

\begin{tabular}{|l|c|c|}
\hline \multicolumn{1}{|c|}{ Benefits } & $\begin{array}{c}\text { Frequency } \\
\text { (Content } \\
\text { Analysis) }\end{array}$ & $\begin{array}{c}\text { Rating Av- } \\
\text { erage (Del- } \\
\text { phi) }\end{array}$ \\
\hline Improved customer service levels & $160(9.5 \%)$ & $3.99(11)$ \\
\hline $\begin{array}{l}\text { Security against theft/fraud/loss/coun- } \\
\text { terfeiting }\end{array}$ & $154(9.14 \%)$ & $3.87(12)$ \\
\hline Reduced out of stock & $135(8.01 \%)$ & $4.36(2)$ \\
\hline Improved data accuracy & $121(7.18 \%)$ & $4.44(1)$ \\
\hline $\begin{array}{l}\text { Accuracy, speed and efficiency of pro- } \\
\text { cess }\end{array}$ & $115(6.82 \%)$ & $4.08(8)$ \\
\hline Realtime visibility & $100(5.93 \%)$ & $4.18(4)$ \\
\hline Reduced inventory & $82(4.87 \%)$ & $4.11(7)$ \\
\hline Increased Sales & $82(4.87 \%)$ & $3.73(18)$ \\
\hline Business Intelligence & $81(4.81 \%)$ & $4.04(9)$ \\
\hline Improved collaboration & $81(4.81 \%)$ & $3.83(13)$ \\
\hline Improved returns/recall management & $81(4.81 \%)$ & $3.75(16)$ \\
\hline Reduced overall cost & $77(4.57 \%)$ & $3.73(19)$ \\
\hline $\begin{array}{l}\text { Improved visibility of orders and inven- } \\
\text { tory }\end{array}$ & $74(4.39 \%)$ & $4.15(6)$ \\
\hline Reduced labor requirements/costs & $70(4.15 \%)$ & $3.54(20)$ \\
\hline Improved on shelf availability & $68(4.04 \%)$ & $4.18(3)$ \\
\hline Reduced shrinkage & $54(3.2 \%)$ & $4.16(5)$ \\
\hline Improved asset management & $52(3.09 \%)$ & $4.01(10)$ \\
\hline Improved labor productivity & $35(2.08 \%)$ & $3.74(17)$ \\
\hline Tracking shopping behavior & $22(1.31 \%)$ & $3.45(21)$ \\
\hline Tracking temperature & $21(1.25 \%)$ & $3.76(15)$ \\
\hline Competitive advantage & $17(1.01 \%)$ & $3.82(14)$ \\
\hline Monitor worker productivity & $3(0.18 \%)$ & $3.25(22)$ \\
\hline Total & 1685 & \\
\hline
\end{tabular}

Table 3. RFID benefits in retail

ISSN: 07I 8-2724. (http://www.jotmi.org)

Journal of Technology Management \& Innovation (c) Universidad Alberto Hurtado, Facultad de Economía y Negocios. 


\begin{tabular}{|c|c|c|c|}
\hline Factors and items & Factor loadings & Eigen-value & $\%$ of variance \\
\hline $\begin{array}{l}\text { Improved operational efficiency }(\alpha=0.883) \\
\text { (Automational) }\end{array}$ & & 3.933 & 17.876 \\
\hline - $\quad$ Reduced labor costs & 0.830 & & \\
\hline - $\quad$ Improved labor productivity & 0.744 & & \\
\hline - $\quad$ Accuracy, speed, and efficiency of processes & 0.695 & & \\
\hline - $\quad$ Reduced overall cost of operations & 0.623 & & \\
\hline - Competitive advantage & 0.603 & & \\
\hline - $\quad$ Improved customer service levels & 0.518 & & \\
\hline $\begin{array}{l}\text { Improved inventory management }(\alpha=0.848) \\
\text { (Informational) }\end{array}$ & & 3.862 & 17.556 \\
\hline - $\quad$ Reduced missing sales & 0.858 & & \\
\hline - $\quad$ Reduced out of stock & 0.852 & & \\
\hline - $\quad$ Reduced inventory & 0.721 & & \\
\hline - $\quad$ Increased sales & 0.619 & & \\
\hline - $\quad$ Business intelligence & 0.457 & & \\
\hline $\begin{array}{l}\text { Improved customer, supplier coordination }(\alpha=0.818) \\
\text { (Informational) }\end{array}$ & & 3.027 & 13.757 \\
\hline - $\quad$ Tracking temperature & 0.754 & & \\
\hline - $\quad$ Tracking shopping behavior & 0.666 & & \\
\hline - $\quad$ Improved returns/recall management & 0.656 & & \\
\hline - $\quad$ Improved collaboration & 0.603 & & \\
\hline - $\quad$ Monitor worker productivity & 0.597 & & \\
\hline $\begin{array}{l}\text { Improved visibility }(\alpha=0.786) \\
\text { (Informational / Transformational) }\end{array}$ & & 2.651 & 12.051 \\
\hline - $\quad$ Improved order visibility & 0.800 & & \\
\hline - $\quad$ Realtime visibility & 0.745 & & \\
\hline - Improved data accuracy & 0.543 & & \\
\hline - $\quad$ Improved asset management & 0.489 & & \\
\hline $\begin{array}{l}\text { Improved security }(\alpha=0.616) \\
\text { (Informational) }\end{array}$ & & 1.924 & 8.745 \\
\hline - $\quad$ Reduced theft/fraud/loss/counterfeiting & 0.845 & & \\
\hline - $\quad$ Reduced shrinkage & 0.669 & & \\
\hline
\end{tabular}

Table 4. Factor analysis of RFID benefits

As it can be seen from Table 4, improved operational efficiency can be achieved by automating operational processes and thus reducing manual intervention and errors. Similarly improved inventory management is an informational effect that can be achieved by improving capabilities to collect, store, process, and disseminate information. Improved customer, supplier coordination is again an informational effect of RFID. Improved visibility is both an informational and transformational effect (Facilitating process engineering). It can be observed that informational effect is the most important benefit of RFID. However transformational effect is where the real potential exists. 


\section{Business Value of RFID in Retail}

After identifying the significant benefits from the two methods and categorizing them in terms of automational, informational, and transformational value dimensions, business values of RFID that are perceived to be more important according to the experts in the Delphi study is investigated. However it is to be noted here that these dimensions or effects are not mutually exclusive. Table 5 below shows the results of the Delphi study. According to the experts, informational effect is the most important business value of RFID, followed by transformation, and automational effects. This is similar to what is observed in Table 4. However transformational effect is where the true revolutionizing capability of RFID lies and retailers must try to achieve it to gain more from the technology. Expert perceptions about RFID business value do not vary across various business associations. However consultants have a more optimistic opinion about informational effect of RFID in comparison to experts from other domains.

\begin{tabular}{|l|c|}
\hline Business Value of RFID & Rating Average \\
\hline Informational & 4.22 \\
\hline Transformational & 3.95 \\
\hline Automational & 3.40 \\
\hline
\end{tabular}

Table 5. Dimensions of RFID business value

\section{Major Challenges for RFID Adoption in Retail}

Starting with the entire set of RFID articles, 359 instances are observed that mention one or more specific RFID adoption challenges. From content analysis twelve challenges that inhibit RFID adoption for retail are identified. Table 6 shows that privacy and cost are the most dominant challenges reported from content analysis. Technical issues such as readability and data integration are also daunting. Other challenges are unclear ROI (Return on investment), multiple frequencies, employee resistance, lack of top management support, lack of technical expertise, and complexity. From the Delphi study, it is verified that the adoption challenges identified by content analysis are indeed important. However the rankings of these challenges from the two methods are different (Table 6).

Factor analysis of initial 12 challenge items reveals four factors with eigen-values greater than 1.0 accounting for about $68 \%$ of the total variance. These factors are: (a) technical challenges (b) organizational challenges (c) fit challenges (issues that capture the link between RIFD processes and the underlying business processes they are intended to support), and (d) business challenges. Specific factor loadings are shown in Table 7. The technical challenges are technological and will gradually fade. The organizational factors are similar to the factors identified in the organizational adoption of technology. These are top management support, IT expertise, organizational size, and organizational readiness.

\begin{tabular}{|l|c|c|}
\hline Challenges & $\begin{array}{c}\text { Frequency } \\
\text { (Content } \\
\text { Analysis) }\end{array}$ & $\begin{array}{c}\text { Rating Average } \\
\text { (Delphi) }\end{array}$ \\
\hline Privacy Issues & $117(32.59 \%)$ & $3.05(9)$ \\
\hline High Cost & $56(15.60 \%)$ & $4.03(1)$ \\
\hline Readability & $54(15.04 \%)$ & $3.30(6)$ \\
\hline Data Warehousing and Integration & $50(13.93 \%)$ & $3.12(8)$ \\
\hline Lack of Standards & $37(10.31 \%)$ & $2.75(11)$ \\
\hline Business Process Redesign & $17(4.74 \%)$ & $3.67(3)$ \\
\hline Unclear ROI & $13(3.62 \%)$ & $3.82(2)$ \\
\hline Multiple Frequencies & $7(1.95 \%)$ & $2.68(12)$ \\
\hline Resistance to change & $5(1.39 \%)$ & $3.32(5)$ \\
\hline Lack of top management support & $1(0.28 \%)$ & $3.67(4)$ \\
\hline Lack of technical expertise & $1(0.28 \%)$ & $3.26(7)$ \\
\hline Complexity of technology & $1(0.28 \%)$ & $2.90(10)$ \\
\hline Total & 359 & \\
\hline
\end{tabular}

Table 6. RFID adoption challenges in retail

ISSN: 07I 8-2724. (http://www.jotmi.org)

Journal of Technology Management \& Innovation (c) Universidad Alberto Hurtado, Facultad de Economía y Negocios. 


\begin{tabular}{|c|c|c|c|}
\hline \multirow{2}{*}{\begin{tabular}{|l|} 
Factors and items \\
Technical challenges $(\alpha=0.883)$ \\
(Technological)
\end{tabular}} & \multirow[t]{2}{*}{ Factor loadings } & \multirow{2}{*}{$\begin{array}{c}\text { Eigen-value } \\
2.786\end{array}$} & \multirow{2}{*}{$\begin{array}{c}\text { \% of variance } \\
23.219\end{array}$} \\
\hline & & & \\
\hline - $\quad$ Readability issues & 0.784 & & \\
\hline - $\quad$ Multiple frequencies & 0.768 & & \\
\hline - $\quad$ Lack of standards & 0.755 & & \\
\hline - $\quad$ Unclear ROI & 0.607 & & \\
\hline - $\quad$ Data warehousing and integration & 0.570 & & \\
\hline $\begin{array}{l}\text { Organizational challenges }(\alpha=0.848) \\
\text { (Organizational) }\end{array}$ & & 2.171 & 18.094 \\
\hline - Employee resistance to change & 0.852 & & \\
\hline - $\quad$ Lack of top management support & 0.845 & & \\
\hline - $\quad$ Lack of technical expertise & 0.636 & & \\
\hline $\begin{array}{l}\text { Fit challenges }(\alpha=0.818) \\
\text { (Technological) }\end{array}$ & & 1.665 & 13.872 \\
\hline - $\quad$ Business process redesign & 0.865 & & \\
\hline - Complexity of the technology & 0.620 & & \\
\hline $\begin{array}{l}\text { Business challenges ( } \alpha=0.786 \text { ) } \\
\text { (Technological) }\end{array}$ & & 1.465 & 12.207 \\
\hline - $\quad$ Privacy issues & 0.781 & & \\
\hline - High cost & 0.768 & & \\
\hline
\end{tabular}

Table 7. Factor analysis of RFID adoption challenges

Employee resistance to change reflected lack of organizational readiness; lack of top management support and lack of technical expertise are the same constructs as identified in literature. The fit challenges are technological and include business process redesign and complexity. The business challenges being privacy and cost are perceived to be the most important.

\section{Comparison of Expert Perceptions across Business Association}

After identifying the most significant adoption drivers, benefits, and implementation, difference in expert perceptions based on their field of business association such as consulting, academia, retail, or third party service providers is investigated. This could give some deeper insights on the current RFID adoption status and also act as a pointer to future research initiatives.

Exploratory statistical analysis of the Delphi data is performed to look for general patterns. Multivariate analysis of variance (MANOVA) and multiple one way analyses of vari- ance (ANOVA) are performed on the adoption drivers, benefits, and implementation challenges data across the expert's business associations. The justification for conducting the MANOVA tests is that there are multiple dependent variables each for adoption drivers, benefits, and implementation challenges and the intention is to examine the differences between the levels of the independent variable (Business association) as a function on the combination of dependent variables (different adoption drivers, benefits, and challenges ). The justification for performing multiple ANOVA tests is that this research is exploratory and also because the dependent variables are conceptually independent of each other i.e. they do not measure the same thing (Biskin, 1980). The goal is to study the effect of business association of experts on their perceptions about the significance of the issues under investigation to reach some tentative non-confirmatory conclusions. Since this is an exploratory study a significance level of $10 \%$ is used to capture any pattern that is close to being significant. The goal is to draw optimal insights from the data analysis.

ISSN: 07 I8-2724. (http://www.jotmi.org) 


\section{Multivariate Analysis of Variance (MANOVA) Results:}

First, a 4 (Business Association) X 6 (Adoption Drivers) multivariate analysis of variance (MANOVA) is conducted to test whether the four groups (Academia, Consulting, Retail, and Third Party Service Providers) are statistically different from each other in terms of their overall perceptions about RFID adoption drivers.

Our null hypothesis is:

HI0: Perceptions about RFID adoption drivers do not vary as a function of the business association of the experts.

The analysis reveals a non-significant main effect for business association. The calculated Wilks' Lambda $=0.809, \mathrm{~F}$ $(18,176)=0.761, p$-value $=0.74(>0.10)$. Since $p$-value is not $<0.10$, the null hypothesis $\mathrm{HIO}$ cannot be rejected at $10 \%$ significance level and conclude that the expert perceptions about RFID adoption drivers do not vary as a function of the expert business associations.

Next, a 4 (Business Association) $X 22$ (Benefits) multivariate analysis of variance (MANOVA) is conducted to test whether the four groups (Academia, Consulting, Retail, and Third Party Service Providers) are statistically different form each other in terms of their overall perceptions about RFID benefits.
Our null hypothesis is:

H20: Perceptions about RFID benefits do not vary as a function of the business association of the experts.

The analysis reveals a non-significant main effect for business association. The calculated Wilks' Lambda $=0.216, \mathrm{~F}$ $(66,100)=1.01, p$-value $=0.480(>0.10)$. Since $p$-value $>0.10$ the null hypothesis $\mathrm{H} 20$ cannot be rejected at $10 \%$ significance level and conclude that the expert perceptions about RFID benefits do not vary as a function of the expert business associations.

Finally, a 4 (Business Association) $\times 12$ (Challenges) multivariate analysis of variance (MANOVA) is conducted to test whether the four groups (Academia, Consulting, Retail, and Third Party Service Providers) are statistically different form each other in terms of their overall perceptions about RFID implementation challenges.

Our null hypothesis is:

H30: Perceptions about RFID implementation challenges do not vary as a function of the business association of the experts.

The analysis reveals a significant main effect for business association. The calculated Wilks' Lambda $=0.484, \mathrm{~F}(36,155)$ $=1.19, \mathrm{p}$-value $=0.23(>0.10)$. Since $\mathrm{p}$-value $>0.10$ the null hypothesis $\mathrm{H} 30$ cannot be rejected at $10 \%$ significance level and conclude that the expert perceptions about implementation challenges do not vary as a function of the expert business associations. The MANOVA tests show that

\begin{tabular}{|l|c|c|c|c|}
\hline \multicolumn{1}{|c|}{ Hypotheses } & Wilk's Lambda & F-Values & P-Values & Results \\
\hline $\begin{array}{l}\text { H1 } 1_{0} \text { Perceptions about } \\
\text { RFID benefits do not vary } \\
\text { as a function of the busi- } \\
\text { ness association of the } \\
\text { experts. }\end{array}$ & 0.809 & 0.761 & 0.10 & Cannot reject $\mathrm{H}_{0}$ \\
\hline $\begin{array}{l}\mathrm{H} 2_{0}: \text { Perceptions about } \\
\text { RFID benefits do not vary } \\
\text { as a function of the busi- } \\
\text { ness association of the } \\
\text { experts. }\end{array}$ & 0.216 & 1.01 & 0.480 & Cannot reject $\mathrm{H}_{0}$ \\
\hline $\begin{array}{l}\text { H3: Perceptions about } \\
\text { RFID implementation } \\
\text { challenges do not vary as } \\
\text { a function of the business } \\
\text { association of the experts. }\end{array}$ & 0.484 & 1.19 & 0.230 & Cannot reject $\mathrm{H} 3_{0}$ \\
\hline
\end{tabular}

Table 8. MANOVA results: Comparison of expert perceptions

ISSN: 07I 8-2724. (http://www.jotmi.org)

Journal of Technology Management \& Innovation (C) Universidad Alberto Hurtado, Facultad de Economía y Negocios. 
the overall expert perceptions about RFID adoption drivers, benefits, and challenges are similar which indicates that there is not any inherent bias within each business association group in our sample for Delphi study. Table 8 below shows the results of the MANOVA tests. Next, univariate analysis of variance tests is performed on each of the dependent variables separately to identify specific differences in perceptions if they exist.

\section{Univariate Analysis of Variance (ANOVA) Results:}

Table 9 below shows the significant univariate analysis of variance ANOVA results that is observed. Out of the 6 adoption drivers, the univariate analysis for perceptions about decreasing cost of tags and readers as an adoption driver reveals a significant main effect $(\mathrm{p}$-value $=0.042 *<$ 0.10 ) for business association with consultants (Mean $=4.32$, Standard Error $=0.78$ ) reporting more favorable perception followed by retail (Mean $=3.94$, Standard Error $=1.00$ ), academics (Mean $=3.59$, Standard Error $=1.00$ ), and finally third party service providers (Mean $=3.44$, Standard Error $=1.29$ ).

Similarly, from the ANOVA results for the perceptions about real-time visibility (out of 22 benefits) as a significant RFID benefit for retail, significant main effect is observed ( $P$-value $=0.040 *)<0.10$ ) for business association with consultants (Mean $=4.50$, Standard Error $=0.67)$ reporting more favorable perception followed by third party service providers $($ Mean $=4.28$, Standard Error $=0.75)$, academics (Mean $=$ 4. 12 , Standard Error $=0.86)$, and finally retail $($ Mean $=3.69$, Standard Error $=1.14$ ).

Finally, from the ANOVA results for the perceptions about high cost as a significant RFID implementation challenge for retail (out of 12 challenges) significant main effect is observed $(p$-value $=0.002 *)<0.10)$ for business association with consultants (Mean $=4.12$, Standard Error $=0.86$ ) reporting more favorable perception followed by retail (Mean $=4.12$, Standard Error $=0.88)$, academics $($ Mean $=4.12$, Standard Error $=0.86$ ), and finally third party service providers $($ Mean $=3.28$, Standard Error $=1.32$ ).

The results of the multiple ANOVA tests indicate that the overall perceptions of retail practitioners is more conserva- tive than those from other domains like consulting, third party service providers, and academics. This indicates that most retailers are still focusing on a small spectrum of RFID possibilities and not considering a broader perspective. Or on the other hand this could indicate a possible hype around RFID improving retail operations across value chain. However it can be seen from the drivers and challenges ANOVA results that the retailers are seeing an increasing opportunity with RFID as cost is gradually decreasing with time.

For future research, it will be interesting to investigate the differences in perceptions of experts from various domains through in-depth interviews. This research could be extended to find out differences if any, across other control variables such as expert job positions, familiarity with RFID, and length of involvement with RFID. Table 9 below shows the results from the significant univariate analysis (ANOVA) tests.

\section{Conclusion}

There is consistency in the items identified as drivers to adoption, benefits and challenges with respect to RFID in both the content analysis and the Delphi study. However, the relative importance of these various items within each of the three categories differs, often markedly. The experts were drawing on direct experience with several years of RFID-related activities. On the other hand, the content analysis includes publications dating to 2006. Even though the content analysis includes publications through April 2009, the discrepancy between content analysis rankings and Delphi expert rankings reflects much of the early hype associated with RFID. The findings from this research suggest that despite the expected impact of retailer and DOD mandates, it is still the technology costs that are driving adoption decisions. With respect to benefits, the anticipated customer service benefits (from the content analysis) appear overshadowed by the more firm-centric inventory and visibility aspects of the technology. Finally, with respect to challenges, the results point to the importance of cost and making the business case as the primary issues rather than the privacy concerns voiced in the content analysis. Overall, it is believed that decision-makers are influenced by cost and by the difficulty in monetizing the benefits of the technology in the normal course of business. It is also observed that

\begin{tabular}{|l|c|c|c|}
\hline Dependent Variables & DF & F-Statistics & P-Value \\
\hline Decreasing cost of tags and readers - Driver 4 & 69 & 2.89 & $0.042^{*}$ \\
\hline Real-time Visibility- Benefit 8 & 69 & 2.91 & $0.040^{*}$ \\
\hline High cost - Challenge 2 & 70 & 5.425 & $0.002^{*}$ \\
\hline
\end{tabular}

Table 9. Significant ANOVA results - Expert perception comparison

ISSN: 07 I8-2724. (http://www.jotmi.org)

Journal of Technology Management \& Innovation (c) Universidad Alberto Hurtado, Facultad de Economía y Negocios. 
there is an overall similarity in the expert perceptions across different business associations with a few exceptions such as decreasing cost as the RFID adoption driver, real-time visibility as a significant RFID benefit, and finally high cost as an implementation challenge.

\section{References}

ALTSCHULD, J.W. (1993). Evaluation methods: Principles of needs assessment II, Delphi Technique Lecture. Department of Educational Services and Research, The Ohio State University.

ASIF, Z and Mandviwalla, M. (2005). Integrating the supply chain with RFID:A technical and business analysis. Communications of the Association for Information Systems, vol. I5, Pp. 393-427.

BAGCHI, U., Guiffrida, A., O'Neill, L., Zeng, A., and Hayya, J.C. (2007). The effect of RFID on inventory management \& control, pp. 7I-92, in Jung, Hosang, F. Frank Chen, and Bongju Jeong (Eds.), Trends in Supply Chain Design and Management: Technologies and Methodologies. London: Springer-Verlag.

BHATTACHARYA, M.B., Chu, C.H., Mullen, T. (2007). RFID implementation in retail industry: Current status, issues, and challenges. Proceedings of 38th Annual Meeting of the Decision Sciences Institute, Phoenix, AZ, 217I-2I 76.

BHATTACHARYA, M., Chu, C.H., and Mullen, T. (2008). A comparative analysis of RFID adoption in retail and manufacturing sectors. Proceedings of IEEE International Conference on RFID, I6-I7 April, Las Vegas, NV, pp. 24I-249.

BHATTACHARYA, M., C.H. Chu, T. Mullen, and Hayya, J.C. (2009). An exploratory study of RFID implementation in retail sector. Proceedings of 40th Annual Meeting of the Decision Sciences Institute, New Orleans, LA, pp. 30 I I-30I6.

BHATTACHARYA, M., Chu, C.H., Mullen, T., and Hayya, J.C. (20I0a).An exploratory study of RFID adoption in the retail sector. Operations Management Research, Vol. 3, no. I-2, Pp. 80-89.

BHATTACHARYA, M., Petrick, I., Mullen, T. (2010b). A delphi study of RFID adoption for business process and value chain optimization. Proceedings of 4 Ist Annual Meeting of Decision Sciences Institute, San Diego, CA, 305I-3056.

BhATTACHARYA, M., Petrick, I., Mullen, T., and Kvasny, L. (20II).A Delphi study of RFID applicable business processes and value chain activities in retail. Journal of Technology and Management Innovations, Vol. 6, no. 3, pp. 64-8I.
BISKIN, B.H. (1980). Multivariate analysis in experimental counseling research. The Counseling Psychologist, vol. 8, pp. 69-72.

BOSE, I. and Pal, R. (2005). Auto-ID: Managing anything, anywhere, anytime in the Supply Chain. Communications of the ACM, vol. 48, no. 8, pp. I00-106.

DALKEY, N.C. (1969). The delphi method: An experimental study of group opinion, Memorandum RM-5888 pr, Santa Monica, Rand Corporation.

DEDRICK, J., Gurbaxani, V., and Kraemer, K.L. (2003). Information technology and economic performance: A critical review of the empirical evidence. ACM Computing Surveys, vol. 35, no. I, pp. I-28.

GRUEN, T.W., Corsten, D.S., and Bharadwaj, S. (2002). Retail out-of-Stocks: A worldwide examination of extent, causes and consumer responses, Grocery Manufacturers of America. The Food Marketing Institute and CIES - The Food Business Forum.

HICKEY, K. (1999). A Diamond in the Rough. Traffic World, vol. 258 , no. 5 .

HOLSTI (1969). Content analysis for the social sciences and humanities. Reading, MA:Addison-Wesley.

JONES, P., Clarke-Hill, C., Shears, P., Comfort, D., and Hillier, D. (2004). Radio frequency identification in the UK: Opportunities and challenges. International Journal of Retail \& Distribution Management, Bradford, vol. 32, no. 2/3, pp. I64- I7I.

KARKKAINEN, M. and Holmstrom, J. (2002). Wireless product identification: Enabler for handling efficiency, customization and information sharing. Supply Chain Management, An International Journal, vol. 7, no. 4, pp. 242-252.

KARKKAINEN, M. (2003). Increasing efficiency in the supply chain for short shelf life goods using RFID tagging. International Journal of Retail and Distribution Management, vol. 3I, no. I0, pp. 529-536.

KRIPPENDORF, K. (2004). Content analysis:An introduction to its methodology. Thousand Oaks, CA: Sage.

LEEDY, P.D. and Ormrod, J.E. (2005). Practical research: Planning and design, 8th Edition. Pearson Merrill Prentice Hall.

LIN, D., Barton, R., Bi, H., and Freimer, M. (2007). Challenges in RFID enabled supply chain management. Quality Progress, vol. 39, no. II, November, 23-28. 
MARKLAND, R.E., Vickery,S.K., and Davis,R.A. (1995). Operations management. South Western College Publishing, Cincinnati.

METRAS, H. (2005). RFID tags for ambient intelligence: Present solutions and future Challenges. Proceedings of the 2005 Joint Conference on Smart Objects and Ambient Intelligence: Innovative Context-Aware Services: Usages and Technologies SOC-EUSAI '05, Grenoble, France, I2I, pp. 4346.

MOONEY, J.G., Gurbaxani, V., and Kraemer, K.L. (1996). A process oriented framework for assessing the business value of information technology. The Data Base for Advances in Information Systems, vol. 27, no. 2, pp. 68-8I.

ORLIKOWSKI, W. (1993). CASE tools as organizational change: Investigating incremental and radical changes in systems development. MIS Quarterly, vol. 17, no. 3, pp. 309-340.

PREMKUMAR, G. and Roberts, M. (1999). Adoption of new information technologies in rural small businesses. International Journal of Management Science, vol. 27, pp. 467-484.

RAMAN, A. (2000). Retail-data quality: Evidence, causes, costs, and fixes. Technology in Society, vol. 22, no. I, pp. 97109.

RANGANATHAN, C. and Jha, S. (2005). Adoption of RFID technology: An exploratory examination from supplier's perspective. Proceedings of the eleventh American conference on information systems, II-I4 August, Omaha, USA, pp. 2195-2199.

RANKY, P.G. (2006). An introduction to radio frequency identification (RFID) methods and solutions. Assembly Automation, vol. 6, no. I, pp. 28-33.

ROBERTI, M. (2002). Wal-Mart, early adopter. Business, vol. 2.0., no. 3, pp. 5.

ROGERS, E.M. (1995). Diffusion of innovations (4th edition) (Ed.), New York:The Free Press.

SCHMIDT, C. (200I). Beyond the bar code. Technology Review, vol. I04, no. 2.

SHARMA, A. and Citurs, A. (2005). Radio frequency identification (RFID) adoption drivers: A radical innovation adoption perspective. Proceedings of the eleventh American conference on information systems, I I-14 August, Omaha, USA, pp. $1213-1218$.
TAJIMA, M. (2007). Strategic value of RFID in supply chain management. Journal of Purchasing \& Supply Management, vol. I3, pp. 26I-273.

VIJAYARAMAN, B.S. and Osyk, B.A. (2006). An empirical study of RFID implementation in the warehousing industry. International Journal of Logistics Management, vol. I7, no. I, Pp. 6-20.

WAMBA, S.F., Lefebvre, L.A., Lefebvre, E. (2007). Integrating RFID technology and EPC network into B2B retail supply chain: A step toward intelligent business processes. Proceedings of the 8th International Conference on Electronic Commerce, Fredericton, New Brunswick, Canada, 28I-288.

WANT, R. (2006). An introduction to RFID technology. IEEE Pervasive Computing, vol. 5, no. I, pp. 25-33.

ZHOU,W. (2009). RFID and item-level information visibility. European Journal of Operational Research, vol. 198, no. I, pp. 252-258. 